\title{
THE EFFICACY OF THE PERIOD OF SACCHARIFICATION ON OIL PALM (ELAEIS GUINEENSIS) TRUNK SAP HYDROLYSIS
}

\author{
Nazia Hossain ${ }^{1,2^{*}}$, Juliana Zaini ${ }^{1}$, Rafidah Jalil ${ }^{3}$, T.M.I. Mahlia ${ }^{4,5}$ \\ ${ }^{1}$ Faculty of Integrated Technologies, Universiti Brunei Darussalam, Jalan Tungku Link, Gadong \\ BE1410, Brunei Darussalam \\ ${ }^{2}$ Department of Biochemical-Biotechnology Engineering, Faculty of Engineering, International \\ Islamic University Malaysia, Jalan Gombak, Kuala Lumpur 50728, Malaysia \\ ${ }^{3}$ Bioenergy Laboratory, Technology Biomass Program, Forest Research Institute Malaysia, Jalan \\ FRIM, Kepong, Kuala Lumpur 52109, Malaysia \\ ${ }^{4}$ Department of Mechanical Engineering, Universiti Tenaga Nasional, 43000 Kajang, Selangor, \\ Malaysia. \\ ${ }^{5}$ School of Systems, Management and Leadership, Faculty of Engineering and Information \\ Technology, University of Technology Sydney, NSW 2007, Australia.
}

(Received: March 2018 / Revised: May 2018 / Accepted: June 2018)

\begin{abstract}
This study investigates the enzymatic hydrolysis rate of Oil Palm (Elaeis guineensis) Trunk (OPT) sap in terms of the length of saccharification process with the aim to elevate sugar production. Emphasis was placed on the reaction time and addition of supplements such epsom salt $\left(\mathrm{MgSO}_{4}\right)$ and alanine amino acid $\left(\mathrm{C}_{3} \mathrm{H}_{7} \mathrm{NO}_{2}\right)$ to accelerate the efficiency of Saccharomyces cerevisiae containing the enzyme invertase. A whole oil palm trunk was divided into four different sections, upper, middle-1, middle- 2 and bottom with separate experiments over 10 days enzymatic reaction period. The highest saccharification rate was shown as $13.47 \%$ on the tenth day. This result indicates that the increase in the saccharification rate was positively correlated with the length of hydrolysis. Moreover, the sample with nutrients achieved the highest sugar output, $17.91 \%$ on the fourth day of hydrolysis which was $4.44 \%$ higher than the hydrolysis rate of the sample without nutrients. In the presence of complex OPT sugars, together with other essential elements, epsom salt and alanine amino acid, S.cerevisiae achieved a higher hydrolysis metabolism to simple sugars as the cells strived to produce energy and regenerated the invertase. Moreover, the upper part of the OPT rendered the highest potential for sugar production with levels of $21.2 \%$ with supplements and $15.6 \%$ without. From this experimental analysis, a conventional saccharification method was optimized through the addition of nutrients and a prolonged (10 days) hydrolysis process which yielded an increase in sugar production.
\end{abstract}

Keywords: Hydrolysis; Hydrolysis time; Oil palm trunk; Saccharification; Saccharomyces cerevisiae; Sugar conversion

\section{INTRODUCTION}

Oil palm (Elaeis guineensis) is one of the most popular edible oil producing cash crops worldwide especially in countries of south-east Asia and Africa. Besides cooking oil, palm oil is used for many other purposes such as a raw material for soap, detergent, cosmetics, noodles,

*Corresponding author's email: bristy808.nh@gmail.com, Tel. +673-8263526

Permalink/DOI: https://doi.org/10.14716/ijtech.v9i4.1808 
biofuel (e.g. bioethanol and biodiesel) and bio-plastic materials amongst others (Kurnia et al.,2016). Among Asian countries, Malaysia, Indonesia and Thailand cultivate oil palm trees mostly for oil production purposes. Oil palm plantations cover significant land areas in Malaysia and Indonesia with approximately 3,741,000 ha in Malaysia and 4,540,000 ha in Indonesia at 2007. Oil palm usually starts to bear fruits for oil production 2.5-3.0 years after planting. After 20-25 years, fruit production stops, so the oil palms need to be replaced with new trees. According to Yamada et al. (2010), 4\% of the total area for both Malaysia and Indonesia is harvested each year which results in around 160 tons/ha oil palm trunk (OPT) waste for each batch (Yamada et al., 2010). In general, the palm oil industries produce a huge quantity of biomass, including palm fibre, palm kernel cake, decanter cake, palm oil mill effluent, palm fruit bunches, shells and fronds after fruit collection and palm trunk after replanting (Kurnia et al., 2016). All palm waste used to be left to rot in palm forests or burned down to piles of ash; later, the ash was redistributed to the plantations as a soil conditioner and fertilizer for nutrition and mulching. However, this mass incineration caused tremendous environmental pollution and hazards such as haze and acid rain as well as triggers the greenhouse effect. To avoid these human-made hazards, much research is currently being conducted on zero waste in palm utilization such as sugar production (food substance), xylitol (food substance), animal feed (food substance), bioethanol (fuel), biodiesel (fuel) and particle board (wood material) from OPT, fronds, fruit shells and kernels (Zainan et al., 2011; Bakar et al., 2012).

Aside from oil production, palm oil trees are traditionally used for palm sugar and palm wine production by tapping their inflorescence as it is done with other palm plants such as date palms, sweet palms, coconut and sago. Among these palm plants, the oil palm renders a comparatively low amount of sugar compared to other types although oil palm plantation is excessively available than other palm species like date palm and others in fact, the oil palm is the most harvested plant for oil production all over the world. Therefore, OPT is projected as a prospective source of sugar; later, this sugar can be treated either as raw bioethanol material or as free sugar for food consumption with further treatments e.g. purification, dehydration and others with extra cost(Yamada et al., 2010; Hamid et al., 2015).

Unlike other wood, OPT sap contains high moisture and a heterogeneous physical and chemical material composition including a huge quantity of short-chain carbohydrates which are great sources of sugar production. Biologically, the inner portion (periphery) of OPT is more carbohydrate-rich compared to the exterior because of the lower number of vascular bundles and higher level of parenchyma tissue. OPT mostly comprises lignocellulose which is composed of polysaccharides (starch with $39.9 \%$ cellulose, $21.2 \%$ hemicellulose) as well as 22.6\% lignin, $1.9 \%$ ash, 3.1\% wax and $11.3 \%$ other constituents (Sun et al., 2008; Kosugi et al., 2010). Cellulose, a glucan polysaccharide, is the predominant constituent of OPT sap and contains large reservoirs of energy which provide actual potential for sugar conversion. In particular, polysaccharides contain many subunits of polymers such as starch and cellulose and with the presence of enzymes such as invertase (present in yeast) with them, these polymers break down into disaccharides such as sucrose and others; the disaccharides then disintegrate into monosaccharides (simple sugar) with the general formula $\left(\mathrm{CH}_{2} \mathrm{O}\right)_{n}$. Reaction 1 illustrates the general sugar conversion from complex carbohydratesto simple sugar form.

$$
\left.\mathrm{C}_{12} \mathrm{H}_{22} \mathrm{O}_{11} \text { (Sucrose) }+\mathrm{H}_{2} \mathrm{O} \text { (Water }\right)=\mathrm{C}_{6} \mathrm{H}_{12} \mathrm{O}_{6} \text { (Glucose) }+\mathrm{C}_{6} \mathrm{H}_{12} \mathrm{O}_{6} \text { (Fructose) }
$$

The most common monosaccharides are hexoses $(n=6)$ (e.g. glucose, fructose etc.) and pentoses $(n=5)$ (e.g. xylose). Biologically glucose is the dominant sugar component in OPT sap sugar constituents (Ishihara et al., 1991; Gnansounou \& Dauriat, 2005; Sun et al., 2008; Koba \& 
Ishizaki, 2014; Choowang \& Hiziroglu, 2015). Table 1 shows the overall sugar content of OPT sap.

Table 1 Sugar present in oil palm trunk sap

\begin{tabular}{cc}
\hline Sugar Component & Contents $(\% \mathrm{w} / \mathrm{w})$ \\
\hline Sucrose & 6.37 \\
Glucose & 84.21 \\
Fructose & 5.20 \\
Xylose & 1.62 \\
Galactose & 1.51 \\
Rhamnose & 0.07 \\
Others & 1.02 \\
\hline
\end{tabular}

Source: Sun et al. (2008), Kosugi et al. (2010)

Sugar production from OPT sap generally depends on several factors such as hydrolysis time, hydrolysis tools (e.g. enzymes, acids etc.), nutrients, $\mathrm{pH}$ and temperature (Koba \& Ishizaki, 2014). This study analyzes the enzymatic hydrolysis process in relation to the enzyme sources, hydrolysis time and the addition of external supplements to the OPT sap samples. Yeast (Saccharomyces cerevisiae) was the hydrolysis tool for this set of experiments. This can generally be used for enzymatic hydrolysis as it contains the enzyme invertase which works as a reaction tool to convert complex sugars into simple one. Enzymatic hydrolysis is superior to other hydrolysis approaches (e.g. acid or basic hydrolysis) due to its' stable cost, ease of availability and environmental benefits (Sun et al., 2008; Koba \& Ishizaki, 2014; Febrianti et al., 2017). Therefore, the main objectives of this study are: (i) to determine the effect of a saccharification time of between 0-10 days on the OPT sap hydrolysis process usingyeast, and (ii) to compare samples with and without nutrientsin terms of their OPT sap hydrolysis rate.

\section{METHODOLOGY}

Figure 1 outlines the overall methodology. Fresh oil palm trunk was transported from a palm forest to the Forest Research Institute Malaysia (FRIM) saw-mill; the OPT sap was extracted using a squeezer machine and concentrated into a thicker sap by heating the sample to be hydrolysed. It was heated at $100^{\circ} \mathrm{C}$ for 2 hours in the presence of several magnetic stirrers (for agitation purposes). Further samples were prepared combined with yeast, distilled water and nutrients. The hydrolysis process was then initiated by an orbital shaker (laboratory based) for the 0-10 day period and sugar content was determined regularly by a sugar refractometer (Magawaza \& Opara, 2015; Bhosale, 2017).

Collection of Raw Material

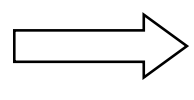

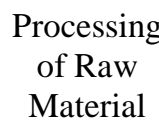

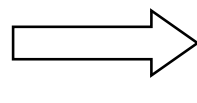

Sample

Preparation
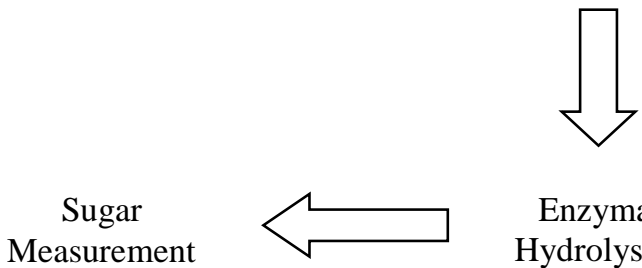

Figure 1 General methodology of the experiment 


\subsection{Raw Material Collection and Processing}

A well-grown, tall (about $8.6 \mathrm{~m}$ ), fresh oil palm trunk was used throughout the study. It was transported from an oil palm forest to the FRIM saw mill, Kepong, Selangor, Malaysia. The whole trunk was logged, timbered out and cut into four different pieces: the upper (UP), middle-1(MID1), middle-2 (MID2) and bottom (BO) by the FRIM saw mill and the different OPT parts were processed separately with similar procedures. Each was chopped into small pieces $(2-4 \mathrm{~cm})$ by a Mobark Chipper Machine (industrial scale). A pilot- sized squeezer then squeezed out the raw OPT pieces. The squeezer had a separation system to separate fibre residue (OPT bagasse) and OPT sap. The sap was collected and filtered with a cheese cloth or sieve to remove all dirt and impurities and then transferred into a pot and taken to the laboratory. Subsequently, the fresh OPT sap was heated on a hot plate for 2 hours at $100^{\circ} \mathrm{C}$ with a magnetic stirrer to concentrate the sap as well as to remove germs and microbes. The concentrated OPT juice was left at room temperature to cool down, poured into an air-tight jar and stored in a freezer for sample preparation.

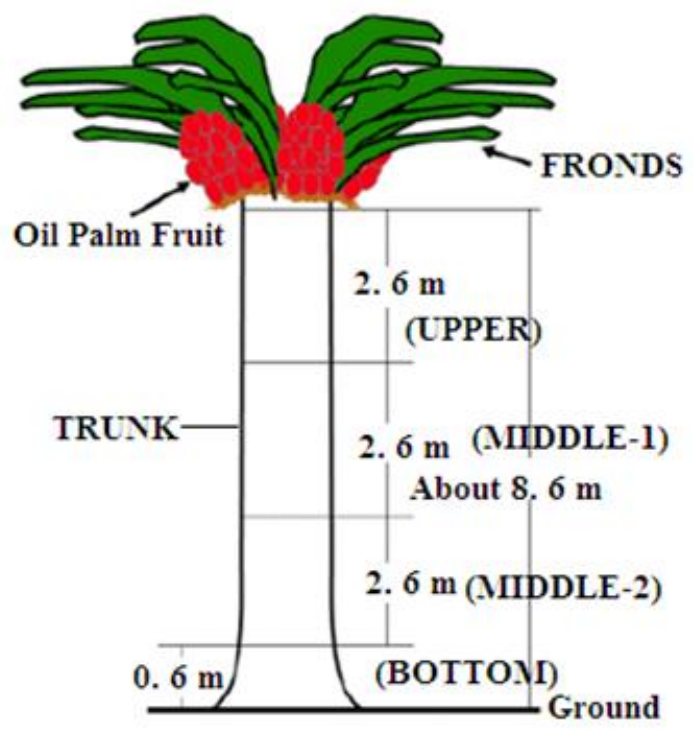

Figure 2 Different OPT sections (Hamid et al., 2010)

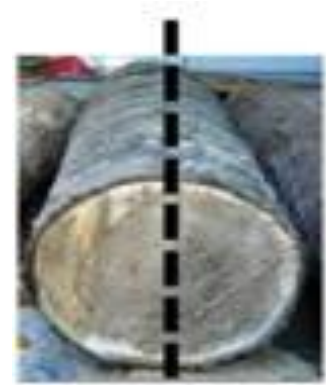

Cut OPT

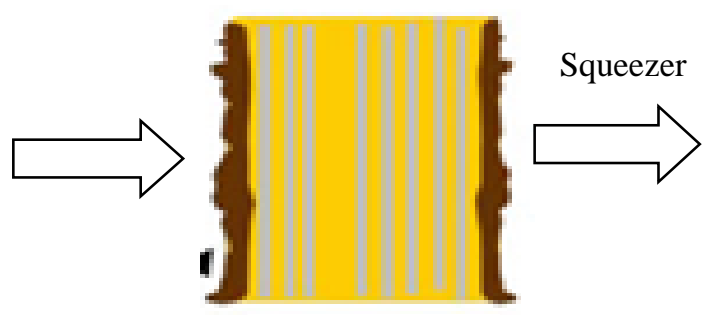

OPT Cross

Section

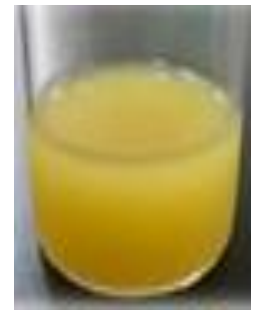

OPT Sap

Figure 3 Raw material processing steps from fresh palm trunk to sap for hydrolysis (Hamid et al., 2015)

\subsection{Sample Preparation}

For the sample preparation, $50 \mathrm{ml}$ from each concentrated OPT sample namely upper (UP), middle-1(MID1), middle-2 (MID2) and bottom (BO) were taken separately. Four conical flasks $(250 \mathrm{ml})$ were used and $50 \mathrm{ml}$ concentrated OPT was poured into each of these. Approximately 
1g Saccharomyces cerevisiae (yeast) (Sigma brand) and $30 \mathrm{ml}$ distilled water were mixed and warmed. The warmed yeast and distilled water mixture was then added into each flask and all three components were mixed smoothly so that the yeast could react effectively with the whole mixture. The flasks were closed air-tight with cotton and aluminium foil. Another set of four samples was prepared by this similar technique albeit extra nutrients were added with the sample. $1 \mathrm{~g}$ of epsom salt $\left(\mathrm{MgSO}_{4}\right)$ (Merck brand) and $1 \mathrm{~g}$ of alanine amino acid $\left(\mathrm{C}_{3} \mathrm{H}_{7} \mathrm{NO}_{2}\right)$ (Sigma brand) were added to each flask as additional supplements with the combination of $1 \mathrm{~g}$ Saccharomyces cerevisiae (yeast), 30ml warmed distilled water and $50 \mathrm{ml}$ OPT sap. $30 \mathrm{ml}$ warmed water has been added to the OPT sap and yeast mixture since $S$. cerevisiae demands high water activity for it to possess a minimum osmotic pressure $\left(\mathrm{a}_{\mathrm{w}}\right)$ of around 0.65 . With the lack of water, the yeast cells may over-produce some co-products such as glycerol or osmolytes (e.g. trehalose) to protect the cell membrane from dehydration which will interrupt maximum sugar production (Walker \& Stewart, 2016). Alanine amino acid, a water soluble organic acid in white powder form acts as an organic nitrogen source for yeast hydrolysis and as a fermentation medium since yeast is a non-diazotrophic micro-fungus that cannot fix atmospheric nitrogen and enhances metabolism by the presence of an assimilable organic nitrogen supply. On the other hand, epsom salt is a water soluble inorganic salt which works as a mineral supplement and plays a significant role in ensuring consistent yeast activity and determining its' hydrolysis performance (Duley et al., 2010; Tohru et al., 2016; Walker \& Stewart, 2016).

\subsection{Enzymatic Hydrolysis by Yeast}

The experiments were carried out with an orbital shaker (Protect brand, Malaysia) in the laboratory. This was set at $160 \mathrm{rpm}, 37^{\circ} \mathrm{C}$ for 96 hours (4 days) and after every 24 hours (1 day) the sugar content was measured regularly in each sample and the flasks returned to the shaker. After 4 days of hydrolysis, all the samples were left at room temperature in a dry and anti-microbial environment for 2 days and the sugar content $(\% \mathrm{w} / \mathrm{w})$ was determined. On the seventh day, the samples were again returned to the orbital shaker with identical parameters for the following four days (day $7-$ day10) and their sugar component was assessed in every 24 hours.

\subsection{Sugar Measurement}

A PAL-1 pocket refractometer (ATAGO U.S.A., Inc., measurement range: brix- $0.0 \%$ to $53 \%$ and temperature range- $9^{\circ} \mathrm{C}$ to $99.9^{\circ} \mathrm{C}$ ) was used to measure the percentage of sugar in each sample. The sample inserting area of the refractometer was first cleaned with distilled water and wiped with tissue or a cotton ball. A small amount was taken from each sample with a dropper and placed on the refractometer sample inserting area for the machine to read the percentage of sugar. All the results were recorded. On each calibration of the refractometer, its' screen was cleaned with distilled water and $70 \%$ alcohol was sprayed onto it to ensure microbe-free sugar measuring surface (Magawaza \& Opara, 2015; Bhosale, 2017).

From the resulting amount of sugar in all the samples, the oil palm trunk sugar content was calculated as an average value using Equation 2 for both sets of samples:

$$
\text { Sugar } \% \text { of } O P T=\frac{\text { Sugar } \% \text { of }(U P+M I D 1+M I D 2+B O)}{4}
$$

UP: upper part, MID1: middle part 1, MID2: middle part 2, BO: bottom part

\section{RESULTS AND DISCUSSION}

The experimental results of the OPT sap with enzymatic hydrolysis indicate that the upper part of the OPT produced a higher sugar content than the other three parts (see Table 2). The stem zone of the oil palm plant contains a greater amount of carbohydrate compounds accumulated 
in the soft and spongy parenchyma tissue than in other parts. Besides having a high amount of parenchyma tissue, the stem is more susceptible to enzymatic attack (Ishihara et al., 1991; Kosugi et al., 2010).

Table 2 Sugar content of OPT sap in terms of enzymatic hydrolysis time

\begin{tabular}{ccccccccc}
\hline \multirow{2}{*}{ Oil Palm Trunk (OPT) Part } & \multicolumn{7}{c}{ Sugar Percentage (\%) of OPT Sap } \\
\cline { 2 - 8 } & Day1 & Day2 & Day3 & Day4 & Day7 & Day8 & Day9 & Day10 \\
\hline Upper & $14.7^{*}$ & $14.9^{*}$ & $14.9^{*}$ & $15.2^{*}$ & 15.4 & 15.27 & 15.3 & 15.6 \\
Middle-1 & $11.8^{*}$ & $11.9^{*}$ & $11.9^{*}$ & $12.2^{*}$ & 12.2 & 12.3 & 12.4 & 12.7 \\
Middle-2 & 11.2 & 11.0 & 11.6 & 11.6 & 11.4 & 11.84 & 12.0 & 12.17 \\
Bottom & $12.4^{*}$ & $12.5^{*}$ & $12.7^{*}$ & $12.7^{*}$ & 13.2 & 13.07 & 13.2 & 13.44 \\
OPT (on Average) & 12.52 & 12.57 & 12.77 & 12.92 & 13.05 & 13.12 & 13.22 & 13.47 \\
\hline
\end{tabular}

*Hossain and Jalil (2015)

As shown in Table 2, the experiments show that enzymatic hydrolysis time has an effect on the saccharification of OPT sap for each part of the OPT, upper, middle-1, middle-2, bottom and whole OPT on average. The average percentage of sugar in the OPT sap consistently increased, from $12.52 \%$ to $13.47 \%$ from day 1 to day 10 indicating that the saccharification rate maintained a positive correlation with increased enzymatic reaction (hydrolysis) time. For this particular process, the increase in sugar content is significantly correlated with the degradation of starch containing carbohydrates. Starch starts the conversion to polysaccharides and from polysaccharides to monosaccharides (simple sugars): glucose and fructose using invertase (yeast containing enzyme). The increasing hydrolysis time accelerates the amount of sugar conversion which triggers the net saccharification output. Usually invertase works as a starchdegrading and sucrose-metabolizing enzyme; it is easily available and cheap to buy. Apart from the hydrolysis time factor, saccharification in the OPT sap also takes place by the induction of invertase triggered by various types of stress such as osmotic stress, water stress and cold stress (Yamada et al., 2010; Hossain \& Jalil, 2015).

Table 2 also demonstrates that sugar accumulation was $12.52 \%$ at initial stage (day 1) and it continuously improved with the hydrolysis time. At the final stage (day 10), saccharification yield was at peak. Usually hydrolysis time are almost done within 12 hours after process initiation, sugars used to be increased thoroughly after 24 hours (1 day) and saccharification continues in terms of reaction time and other factors (Kosugi et al., 2010).

The experimental results of OPT sap with the epsom salt $\left(\mathrm{MgSO}_{4}\right)$ and alanine amino acid $\left(\mathrm{C}_{3} \mathrm{H}_{7} \mathrm{NO}_{2}\right)$ supplements shown in Table 3 display much higher sugar accumulation in each parts than the OPT sap without supplements. Among the four OPT parts, the upper part exhibited the highest saccharification and middle-1 showed the least. On average, saccharification of OPT sap with nutrients was $4.67 \%$ higher than without nutrients in the initial period (day 1), $4.99 \%$ higher on the fourth day and $4.37 \%$ higher on the seventh day. This experimental data set proves that saccharification with supplements was at its peak on the fourth day, in comparison tosaccharification without supplements. It should be stated that the presence of nutrients triggered sugar conversion in the process and that theaddition of supplements made the process more effective and efficient although the addition of nutrients did also add some extra cost. Cost effective analysis and optimization of the process might present a clearer idea of the efficiency of saccharification with supplements in further studies. 
Table 3 Sugar content of OPT (with supplements) in terms of enzymatic hydrolysis time

\begin{tabular}{cccccc}
\hline \multirow{2}{*}{ Oil Palm Trunk (OPT) Part (With Supplements) } & \multicolumn{5}{c}{ Sugar Percentage (\%) of OPT } \\
\cline { 2 - 6 } & Day1 & Day2 & Day3 & Day4 & Day7 \\
\hline Upper & $20.34^{*}$ & $20.6^{*}$ & $21.2^{*}$ & $21.14^{*}$ & 20.7 \\
Middle-1 & $16.24^{*}$ & $16.77^{*}$ & $16.87^{*}$ & $16.97^{*}$ & 16.54 \\
Middle-2 & 15.47 & 15.8 & 15.97 & 16.14 & 15.7 \\
Bottom & $16.74^{*}$ & $17.34^{*}$ & $17.17^{*}$ & $17.4^{*}$ & 16.74 \\
Oil Palm Trunk (on Average) & 17.19 & 17.62 & 17.80 & 17.91 & 17.42 \\
\hline
\end{tabular}

*Hossain and Jalil (2015)

Table 3 also shows that enzymatic hydrolysis with nutrients is correlated with the percentage of saccharification. From day 1 to day 4, the total sugar accumulation increased continuously for almost all the parts and on day 4 it was at its' highest $17.91 \%$ (on average) which is almost 5\% higher than the sample without nutrients. The nitrogen supplement (alanine amino acid) in the sample medium played an anabolic role in the biosynthesis of the structural and functional proteins (invertase) and nucleic acid as well as playing a catabolic role in the hydrolysis. Besides the nitrogen sources, the inorganic salt (epsom salt) contributed a high level of inorganic and bioavailable metal ions, magnesium and sulphur to the sample medium which ensured maximum sugar hydrolysis (Walker \& Stewart, 2016). However, on day 7 the saccharification rate fell for all parts of the OPT; on average it was $17.42 \%$ which was $0.49 \%$ lower than on day 4. This was due to nutrient depletion since the nitrogen sources (amino acids) and minerals $(\mathrm{Mg})$ act as limiting components in hydrolysis or fermentation media (Walker \& Stewart, 2016).

The invertase became more efficient by consuming nutrients as its' added food and worked more effectively for sugar conversion. However, although the effect of the nutrients worked perfectly until day 4 , it then started to fall. It should therefore be concluded that with the increase in hydrolysis time, the saccharification amount increased for both sets of samples (with and without nutrients) but with the nutrients, the yield increased until day 4 and on day 7 , the nutrient loss was the main factor of lower saccharification yield rather than hydrolysis time. If extra nutrients would be added to the sample with nutrients after the fourth day, the saccharification yield might be higher. To emphasize the significance of hydrolysis time on saccharification yield, Bakar et al. (2012) stated that "Enzyme concentration might have lesser effect on cellulose hydrolysis compared to the effect of hydrolysis or reaction time and even at low enzyme loading, more efficient hydrolysis can be achieved with a prolonged incubation time. Increasing dosage of enzymes in an enzymatic process to a certain extent would significantly increase the cost."

Table 2 shows that the saccharification yield without supplements improved continuously from day 1 to day 10 . On the other hand, Table 3 indicates that with the presence of additional supplements, the saccharification rate improved from day 1 to day 4 . After leaving the sample at room temperature fortwo days, onday 7 it showed a decline insaccharification for all the OPTparts. It was concluded that the saccharification had decreased with certain timeperiod and the experiment was not continued further after day 7. This study was a continuation of that of Hossain and Jalil (2015). According to Hossain and Jalil (2015), from day 1 to day 4, the saccharification rate for OPT increased continuously while this study has extended this finding identifying the further saccharification until day 10 (shown in Table 2) and day 7 (shown in Table 3). The previous study outlined the increased OPT saccharification rate from day 1 to 4 for both samples, with and without supplements. This study, however, has shown that the saccharification rate increased until day 10 for the OPT sample without nutrients while in the sample with nutrients, the rate started to decrease after day 4. 
Both sets of experiments indicate that the upper part of the OPT produced the highest amount of sugar, at $15.6 \%$ on day 10 (without supplements) and $21.2 \%$ on day 3 (with supplements). This took place because the upper part of the OPT contains a higher amount of parenchyma and a lower amount of vascular bundles. Parenchyma usually absorbs more moisture because of its' structure (air canals exist between the lobbed cells) and because it contains a huge amount of water and nutrients. On the other hand, the vascular bundle properties are less hygroscopic than those of parenchyma and contain more fibres (Ishihara et al., 1991). Another factor is that the nutrient and moisture content of parenchyma uses more $\mathrm{CO}_{2}$ from nature and absorbs solar energy through chlorophyll producing a high amount of carbohydrate which is the main source of sugars. The starch content (carbohydrate) in the vascular bundles is about $2.4 \%$ and the level of parenchyma in OPT is about $55.4 \%$ (Hamid et al., 2010). In comparison with this, the lower parts of the OPT contain more lignin than carbohydrate, due to the thickening of the older vascular bundles, and the fibres are more lignified and contain thicker cell walls. As lignin structure is generally complex, they are resistant to microbial or many chemical agents (Ishihara et al., 1991; Kosugi et al., 2010; Yamada et al., 2010). With regard to the various studies in progress on OPT such as the production of fibre, particle board, bio-plastics, bio-energy (heat, charcoal, torrefied wood) amongst others, these uses would be more suited to the fibrous parts such as in the bottom and middle rather than upper part. Oil palm deforestation usually generates a massive amount of OPT from which the upper OPT could be used for sugar production and the lower parts for other purposes resulting in optimal usage of OPT and the production of more value added products.

Yamada et al. (2010) reported that the fermentable sugar amount in OPT sap was $12.8 \%$ on average while the previous most popular sugar producing plant, sugarcane, contained $14.5 \%$ sugar content which illustrates that OPT only contains $1.7 \%$ less sugar. Moreover, OPT is producting sugar 136-148 tons/ha, while that of sugarcane is only 77.6 tons/ha; the amount of sugars contained $(\mathrm{g} / \mathrm{kg})$ by OPT is $87 \mathrm{~g} / \mathrm{kg}$ while for sugarcane it is $107 \mathrm{~g} / \mathrm{kg}$ and possible bioethanol yield for OPT sugar fermentation is $8.7-9.4 \mathrm{~m}^{3} /$ ha whereas bioethanol production in the case of the sugar fermentation of sugarcane is $6.5 \mathrm{~m}^{3} /$ ha. These comparisons clarify that OPT sap saccharification has excellent potential for sugar production and this sugar can be a great source of either free sugar or a raw material for bioethanol. Besides oil production, the oil palm plant can produce sugar from its' trunk without interrupting the food chain unlike sugarcane or other sugar producing plants (Sun et al., 2008; Yamada et al., 2010).

To optimize the saccharification process of OPT sap, co-products and by-products could be produced besides the main product, free sugar. Bioethanol and xylitol could be produced as coproducts and bioethanol and carbondioxide $\left(\mathrm{CO}_{2}\right)$ as by-products of the process (Manaf et al., 2018). After cellulosic hydrolysis (enzymatic reaction) of OPT by invertase (Saccharomyces cerevisiae containing enzyme), hexoses $(n=6)$ such as glucose and fructose are produced which are easily fermentable (simple) sugars and could be either a source of free sugar (a food substance) after certain seperation and purification processes or a source of raw materials for bioethanol production. Besides saccharification, fermentation can be continued in the process, and with the increased enzymatic hydrolysis period, bioethanol production can also be increased (with or without supplements) with sugar increase (Hossain \& Jalil, 2015). Almost $20 \%$ of OPT contains an average content of pentoses $(n=5)$ such as xylose, arabinose, arabitol and others. Pentoses can be converted to xylitol by using easily available yeasts, Candida guilliermondii or Candida tropicali; this is a valuable alternative sweetener over sugar which is similar to sucrose in sweetness but is anti-carcinogenic and metabolized by an insulinindependent pathway unlike sugar, so it could be a great source for anti-diabetic food production clinically (Hossain et al., 2017). Figure 4 outlines the process of the development planning of the enzymatic hydrolysis (saccharification) of oil palm trunk (OPT) sap. 
Oil Palm Trunk Sap

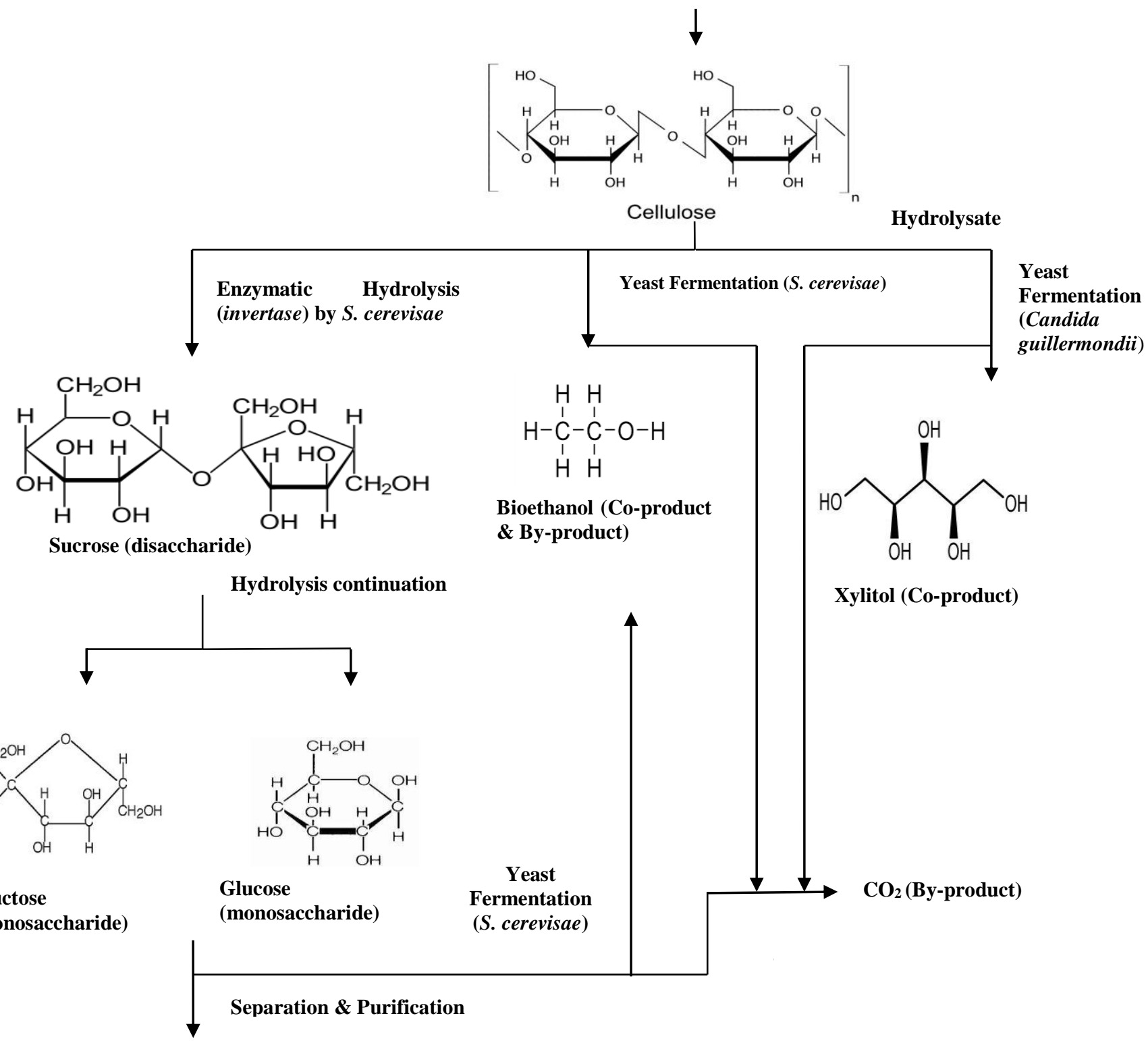

Free Sugar (Main Product)

Figure 4 Process development of enzymatic hydrolysis (saccharification) of oil palm trunk (Hossail et al., 2017; Manaf et al., 2018)

\section{CONCLUSION}

In this study, OPT sap has been analyzed for saccharification by enzymatic hydrolysis within a 10 days hydrolysis period. The sugar content was found to increase in line with the increase in hydrolysis period, up until the tenth day of hydrolysis. The saccharification rate improved greatly when extra supplements were added to the process but these started to decrease in effectiveness after the fourth day of hydrolysis, so the addition of nutrients to the sample after this time is required for the desired sugar accumulation. The use of a genetically modified strain in the hydrolysis process of saccharification to increase the sugar conversion percentage is recommended for further research. 


\section{ACKNOWLEDGEMENT}

This research was supported financially by an FIC Research Grant of Universiti Brunei Darussalam. The award of aYayasan Khazanah Asia Scholarship to Nazia Hossain, Department of Biochemical-Biotechnology Engineering of International Islamic University Malaysia (IIUM), Bioenergy Laboratory of Forest Research Institute Malaysia (FRIM) is also gratefully acknowledged.

\section{REFERENCES}

Bakar, N.K.A., Zanirun, Z., Abd-Aziz, S., Ghazali, F.M., Hassan, M.A., 2012. Production of Fermentable Sugars from Oil Palm Empty Fruit Bunch using Crude Cellulase Cocktails with Trichoderma Asperellum UPM1 and Aspergillus Fumigatus UPM2 for Bioethanol Production. BioResources, Volume 7(3), pp. 3627-3639

Bhosale, A.A., 2017. Detection of Sugar Content in Citrus Fruits by Capacitance Method. Procedia Engineering, Volume 181, pp. 466-471

Choowang, R., Hiziroglu, S., 2015. Properties of Thermally-compressed Oil Palm Trunks (Elaeis guineensis). Journal of Tropical Forest Science, Volume 27(1), pp. 39-46

Duley, L., Henderson-Smart, D.J., Walker, G.J., Chou, D., 2010. Magnesium Sulphate versus Diazepam for Eclampsia. The Cochrane Database of Systematic Reviews, Volume 12

Febrianti, F., Syamsu, K., Rahayuningsih, M., 2017. Bioethanol Production from Tofu Waste by Simultaneous Saccharification and Fermentation (SSF) using Microbial Consortium. International Journal of Technology, Volume 8(5), pp. 898-908

Gnansounou, E., Dauriat, A., 2005. Ethanol Fuel from Biomass: A Review. Journal of Scientific and Industrial Research, Volume 64, pp. 809-821

Hamid, Z.A.A., Sulaiman, O., Hashim, R., Arai, T., Mori, Y., Tanaka, R., Kosugi, A., Murata, Y., Yamamoto, K., 2010. Effect of Storage Time on Starch Content of Oil Palm. In: Proceedings International Conference on Environmental Research and Technology (ICERT 2010), Penang, Malaysia, pp. 59-61

Hamid, Z.A.A., Arai, T., Fatimah, M.R.S., Kosugi, A., Sulaiman, O., Hashim, R., Nirasawa, S., Ryohei, T., Lokesh, B.E., Sudesh, K., Murata, Y., Saito, M., Mori, Y., 2015. Analysis of Free Sugar and Starch in Oil Palm Trunks (Elaeis Guineensis Jacq.) from Various Cultivars as Feedstock for Bioethanol Production. International Journal of Green Energy

Hossain, N., Zaini, J., Mahlia, T.M.I., 2017. A Review of Bioethanol Production from Plant Based Waste Biomass by Yeast Fermentation. International Journal of Technology, Volume 8(1), pp. 5-18

Hossain, N., Jalil, R., 2015. Sugar \& Bioethanol Production from Oil Palm Trunk (OPT). Asia Pacific Journal of Energy \& Environment, Volume 2(5), pp. 89-92

Ishihara, T., Akmar, P.F., Raman, I.A., Khoo, K.C., 1991. Enzymatic Saccharification of Oil Palm Trunks. Journal of Tropical Forest Science, Volume 3(4), pp. 356-360

Koba, Y., Ishizaki, A., 2014. Chemical Composition of Palm Fibre and Its Feasibility as Cellulosic Raw Material for Sugar Production. Agricultural and Biological Chemistry, Volume 54(5), pp. 1183-1187

Kosugi, A., Tanaka, R., Magara, K., Murata, Y., Arai, T., Sulaiman, O., Hashim, R., Hamid Z.A., Yahya, M.K., Yusof, M.N., Ibrahim, W.A., Mori, Y., 2010. Ethanol \& Lactic Acid Production using Sap Squeezed from Old Oil Palm Trunks Felled for Replanting. Journal of Bioscience and Bioengineering, Volume 110(3), pp. 322-325

Kurnia, J.C., Jangam, S.V., Akhter, S., Sasmito, A.P., Mujumdar, A.S., 2016. Advances in Biofuel Production from Oil Palm and Palm Oil Processing Wastes: A Review. Biofuel Research Journal, Volume 3(1), pp. 332-346 
Magawaza, L.S., Opara, U.L., 2015. Analytical Methods for Determination of Sugars and Sweetness of Horticultural Products-A Review. Scientia Horticulturae, Volume 184, pp. 179-192

Manaf, S.F.A., Jahim, J.M., Harun, S., Luthfi, A.A.I., 2018. Fractionation of Oil Palm Fronds (OPF) Hemicellulose using Dilute Nitric Acid for Fermentive Production of Xylitol. Industrial Crops and Products, Volume 115, pp. 6-15

Sun, R., Fang, J.M., Mott, L., Bolton, J., 2008. Extraction and Characterization of Hemicelluloses and Cellulose from Oil Palm Trunk and Empty Fruit Bunch Fibres. Journal of Wood Chemistry and Technology, Volume 19(1-2), pp. 167-185

Tohru, Y., Toru, N., Hiroshi, H., 2016. D-Amino Acids: Physiology, Metabolism and Application. Springer

Walker, G.M., Stewart, G.G., 2016. Saccharomyces cerevisiae in the Production of Fermented Beverages. Beverages, Volume 2(4), pp. 1-12

Yamada, H., Tanaka, R., Sulaiman, O., Hashim, R., Hamid, Z.A.A., Yahya, M.K.A., Kosugi, A., Arai, T., Murata, Y., Nirasawa, S., Yamamoto, K., Oharaa, S., Yusof, M.N.M., Ibrahim, W.A., Mori, Y., 2010. Old Oil Palm Trunk: A Promising Source of Sugars for Bioethanol Production. Biomass and Bioenergy, Volume 34(11), pp. 1608-1613

Zainan, N.H., Alam, M.Z., Al-Khatib, M.F., 2011. Production of Sugar by Hydrolysis of Empty Fruit Bunches using Palm Oil Mill Effluent (POME) Based Cellulases: Optimization Study. African Journal of Biotechnology, Volume 10(81), pp. 18722-18727 